\title{
Análise morfológica de um texto Tupí
}

\author{
Aryon Dall'Igna Rodrigues
}

\section{Introdução}

1. Ainda não se publicou nenhum estudo amplo da morfologia do Tupí antigo. Embora esta língua venha, há mais de 15 anos, sendo objeto de estudo em centros universitários, ainda não apareceu nenhuma descrição moderna de sua estrutura. ${ }^{1}$ No presente artigo não se pretende fazer metódica descrição da morfologia tupí, mas procura-se descrever e comentar diversos aspectos dela, através da análise que se fará de um texto. As formas que ocorrem no texto constituem a motivação para o estudo das principais características da gramática tupí.

2. Este trabalho tem mais uma finalidade didática: proporcionar, aos que querem iniciar-se no estudo do Tupí antigo, um conhecimento dos principais fatos da morfologia desta língua. Procurou-se, por isso, simplesmente expor os fatos, em vez de debatê-los, pois que o debate de muitos fatos que estão sujeitos a interpretação viria confundir o iniciante. $\mathrm{O}$ autor expõe, por essa razão, a sua própria interpretação desses fatos, a qual pode não coincidir com

1. Os estudos de morfologia que têm aparecido, desde a fundação, em 1935, da Cadeira de Língua Tupí-Guaraní na Universidade de São Paulo, são as teses dos professores daquela cadeira, Plinio Ayrosa (1939) e Carlos Drumond (1946), e diversos artigos de Lemos Barbosa, da Universidade Católica do Rio de Janeiro $(1941,1947,1951)$ e de Dall'Igna Rodrigues (1947, 1950a, 1950b, 1950c, 1951a, 1951b, 1951c). Também há observações acerca da morfologia na edição de Ayrosa dos "Poemas Brasílicos" de Cristóvão Valente (Ayrosa, 1941) e na "Contribuição para o estudo do teatro tupí de Anchieta", de Paula Martins (Paula Martins, 1941), bem como nas notas críticas de Lemos Barbosa sobre "Traduções de Poesias Tupis" (Lemos Barbosa, 1949). Merecem especial referência os artigos de Lemos Barbosa "Juká - o paradigma da conjugação tupí" (1941) e "Nova categoria gramatical em Tupí" (1947). O mesmo especialista está publicando um curso de Tupí antigo. 
a de outros estudiosos, como de fato não coincide num ou noutro caso; a interpretação aqui dada mostra, porém, a sua preferência. Sendo o Tupí antigo (sécs. XVI-XVII) uma língua morta, apenas atestada documentalmente, todo o estudo que dela se faz há de ser baseado em documentos: gramáticas, vocabulários e textos; esse estudo é, pois, de cunho nitidamente filológico. Não há lugar, portanto, para contribuição pessoal do autor senão na interpretação e na sistematização de fatos registrados há mais de três séculos.

3. Não menos que a interpretação dos fatos da língua, também a terminologia aqui empregada está sujeita à crítica de outros estudiosos. Como ainda se estão iniciando os estudos de gramática tupí, não há uma nomenclatura firmada para os fenômenos da língua: a sistematização reclama nomes para distinguir os fenômenos, e nem sempre é fácil achá-los convenientes. Em muitos casos de nomenclatura, que ocorrem neste trabalho, o próprio autor não está satisfeito. Entretanto, o que importa mais que a nomenclatura sempre são os fatos, e que esses fatos sejam verdadeiros.

4. Não se obedeceu a nenhum critério especial para a escolha do texto. $\mathrm{O}$ ideal para um estudo seria um texto indígena espontâneo. Tal, porém, é impossível pretender, porque a documentação linguística do Tupí antigo (sécs. XVI-XVII) não compreende nenhum texto dessa natureza: os missionários e cronistas não nos legaram nenhuma reprodução de peças da literatura oral dos antigos Tupinambá. Grande parte dos escritos jesuíticos são composições poéticas, nas quais forçosamente desaparece a naturalidade da língua; assim mesmo, alguns dos textos que mais naturais se apresentam são algumas passagens do "Auto de São Lourenço" de Anchieta. Os principais escritos em prosa são os catecismos, também nada espontâneos. Apresentam maior naturalidade o célebre colóquio de Léry e alguns brevíssimos textos que Abbeville reproduz, dos índios que com ele foram à França.

5. O texto escolhido foram os primeiros doze versos da "Dança de Dez Meninos", de José de Anchieta. A peça toda consta de quarenta versos, distribuídos em dez quadras. A análise de todo o texto levaria ao exame de quase toda a morfologia tupí, o que sairia fora do objetivo deste trabalho.

O manuscrito da "Dança de Dez Meninos" é do próprio punho de Anchieta; data, pois, da segunda metade do século $\mathrm{XVI}^{2}$. O original acha-se nos arquivos da Companhia de Jesus em Roma e fotocópias foram publicadas pela Dra. Paula Martins, acompanhadas de transcrição e tradução, no Bole-

2. Pode-se datar mais precisamente o texto, sabendo-se que deve ter sido composta a "Dança de Dez Meninos" para recepcionar o pe. Marçal Beliarte, chegado ao Brasil em 1587. Cf. Paula Martins, 1945, p. 85. Vide nota final n. ${ }^{\circ} 2$.

3. A tradução é em versos de autoria de Horácio de Carvalho, mas baseada na tradução em prosa do próprio Gen. Couto de Magalhães. Cf. Couto de Magalhães, 1940, pp. 326-327. 
tim n. ${ }^{\circ} 6$ da Cadeira de Etnografia e Língua Tupí-Guaraní da Faculdade de Filosofia da Universidade de S. Paulo (Paula Martins, 1945). A primeira e a terceira estrofes foram publicadas também pelo Gen. Couto de Magalhães, já em 1897, na sua conferência sobre "Anchieta, as raças e línguas indígenas", a qual, desde 1913, tem sido reeditada como apêndice de "O Selvagem" (Couto de Magalhães, 1940). A reprodução de Couto de Magalhães, que não informa onde obteve o texto, apresenta diversos erros de cópia e a tradução que ele acrescenta não tem nenhum valor, pois é uma tentativa infeliz de adivinhar o que dizem as palavras do Tupí antigo .

A cópia de Paula Martins (1945, p. 21) apresenta dois erros de leitura, que corrigimos em nossa transcrição. São os seguintes: Paula Martins leu uijeborimboripa e transcreveu uijeborymbory'pa onde o manuscrito traz uijĕborimboripa que transcrevemos ûîemborymbory'pa (9); a mesma editora leu roripa e transcreveu rorypá onde o manuscrito traz ruripa, que transcrevemos rúripá (12). Se o primeiro defeito é sem importância para a compreensão do texto, o mesmo não se dá com o segundo, que acarretou uma tradução errônea.

6. A transcrição aqui feita do texto é, pois, baseada diretamente no manuscrito original, cuja fotocópia foi publicada por Paula Martins. Substituíram-se as seguintes letras do original: $o$ e $u$ por $\hat{u}$ (quando representam a semivogal); $j, y$ e $i$ por $\hat{\imath}$ (quando representam a semivogal); $i$ por $y$ (quando representa a vogal velar não arredondada); qu e $c$ (diante de $a$ o $u$ ) por $k$; $c$ (diante de $e$ ) por $s$. Com o acento agudo foram assinaladas as sílabas dotadas de intensidade preponderante. $\mathrm{O}$ til, quando abreviatura de $m$, foi substituído por esta letra.

\section{Bibliografia}

\section{Abbeville, Claude D'}

1945. História da missão dos padres capuchinhos na ilha do Maranhão e terras circunvizinhas, trad. de Sérgio Milliet, Bibl. Hist. Bras., vol. XV. S. Paulo.

\section{Adam, Lucien}

1896. Matériaux pour servir à l'établissement d'une grammaire comparée des dialectes de la famille Tupi. Bibl Ling. Américaine t. XVIII. Paris.

\section{Anônimo}

1938. Vocabulário na língua brasílica. Manuscrito português-tupi do séc. XVII, coordenado e prefaciado por Plínio Ayrosa. Col. do Dep. de Cultura, vol. XX. S. Paulo. 
Anchieta, José (PH)

1933. Arte de gramática da língua mais usada na Costa do Brasil, feita pelo p.... Ed. da

Bibl. Nacional do Rio de Janeiro. Rio. (É idêntica a edição da Editora Anchieta, S.

Paulo, 1946: ambas são fac-símiles da ed. príncipe, Coimbra,1595).

1948. Auto representado na festa de S. Lourenço. Peça trilíngue do séc. XVI, transcrita, comentada e traduzida, na parte tupi, por M. de L. de Paula Martins. Museu Paulista, Boletim 1, Documentação Linguística, 1. S. Paulo.

\section{Ayrosa, Plínio}

1939. Dos índices de relação determinativa de posse no tupi-guarani, Univ. de S. Paulo,

Faculd. de Filos., Ciências e Letras, bol IX, Etnografia Brasileira e Língua TupiGuarani, n. ${ }^{\circ}$ 1. S. Paulo.

1941. Poemas brasílicos do pe. Cristóvão Valente, S. J. (notas e tradução). Univ. de S.

Paulo, Faculd. de Filos., Ciências e Letras, bol. XXIII, Etnografia e Língua TupiGuaráni, n. ${ }^{\circ}$ 2, S. Paulo.

\section{Couto de Magalhães, Gen. (José Vieira)}

1940. O selvagem. $4^{\text {a }}$ ed. completa. Bibl. Pedag. Bras., série $5^{\text {a }}$, vol. 52. S. Paulo - Rio - Recife - P. Alegre.

\section{Dall'igna Rodrigues, Aryon}

1947. A categoria de voz em Tupi. Logos, ano II, n. 6 , pp. 50-53. Curitiba. 1950a. A categoria de tempo em Tupi. Gazeta do Povo, 17-II-50. Curitiba. 1950b. A categoria de voz em Tupi, Gazeta do Povo, 10-III-50. Curitiba. 1950c. A reduplicação em Tupi. Gazeta do Povo, 31-III-50. Curitiba. 1951a. Formas deverbativas em Tupi. Gazeta do Povo, 5-VIII-51. Curitiba. 1951b. A categoria de aspecto em Tupi. Gazeta do Povo, 28-X-51. Curitiba. 1951c. A composição em Tupi. Logos, ano VI, n. ${ }^{\circ} 14$, pp. 63-70. Curitiba.

\section{Drumond, Carlos}

1946. Da partícula háb.a do tupi-guarani, Univ. de S. Paulo, Faculd. de Filos., Ciências e Letras, bol. LXVI, Etnografia e Língua Tupi-Guarani, n. ${ }^{\circ} 12$. S. Paulo.

\section{Fernandes, Florestan}

s. d. A organização social dos Tupinambá, S. Paulo.

\section{Figueira, Luis}

1880. Arte de grammatica da lingua brasilica do padre... Nova edição dada à luz e anotada por Emilio Allain. Rio de Janeiro. 


\section{Lemos Barbosa, A(ntónio)}

1941. Juká - o paradigma da conjugação tupi. Estudo etimológico-gramatical. Rev. Filológica, ano II, n. ${ }^{\circ}$ 12, pp. 74-84. Rio de Janeiro.

1947. Nova categoria gramatical tupi. Verbum, t. IV, fasc. 2, pp. 67-74. Rio de Janeiro. 1949 Traduções de poesias tupis. Rev. do Arquivo Municipal, vol. 128, pp. 27-44. S. Paulo.

1951. Pequeno vocabulário tupi-português. Rio de Janeiro.

\section{Léry, Jean De}

1926. História de uma viagem à terra do Brasil. Trad. de Monteiro Lobato. S. Paulo -

Rio de Janeiro.

\section{Marcgrave, Jorge}

1942. História natural do Brasil. Trad. de J. P. de Magalhães, ed. do Museu Paulista.

S. Paulo.

\section{Métraux, Alfred}

1928. La religion des Tupinamba et ses rapports avec celle des autres tribus tupi-guarani.

Bibl. de l'École des Hautes Études, Sciences Religieuses, vol. 45. Paris.

\section{Montoya, Antonio Ruiz de}

1876a. Arte de la lengua guarani, ó mas bien tupi, por el P. ... Nueva edición. Viena - Paris.

1876b. Vocabulario y tesoro de la lengua guarani, ó mas bien tupi, por el P. ... Nueva edición. Viena - Paris.

\section{Paula Martins, M(aria) de L(ourdes)}

1941. Contribuição para o estudo do teatro tupi de Anchieta. Diálogo e trilogia (segundo manuscritos originais do séc. XVI). Univ. de. S. Paulo, Faculd. de Filos., Ciências e Letras, bol. XXIV, Etnografia e Língua Tupi-Guarani, n. ${ }^{\circ}$ 3. S. Paulo.

1945. Poesias tupis (século XVI). Univ. de S. Paulo, Faculd. de Filos., Ciências e Letras, bol. LI, Etnografia e Língua Tupi-Guarani, n. 6: S. Paulo.

\section{Res'tivo, Paulo}

1892. Linguae guarani grammatica Hispanice a Rev. P. Jes. ..., redimpressa necnon prefatione notisque instructa opera et studiis Christiani Frederici Seybold. Stuttgardiae.

\section{Texto}

O texto é apresentado com a separação, por meio de hífens, de todos os elementos mórficos que constituem os vocábulos. Na medida do possível, para 
facilitar o entendimento, é dada a tradução literal de cada elemento significativo, a qual é colocada interlinearmente. A tradução normal é dada a seguir. Cada palavra vai seguida de um número, que será usado como referência para a análise.

Dança de dez meninos

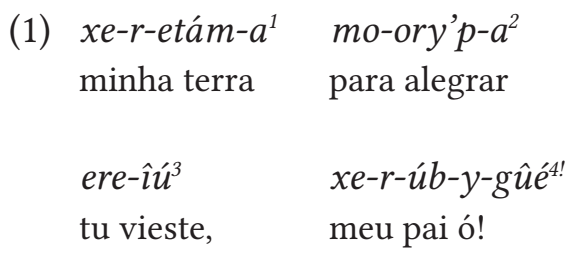

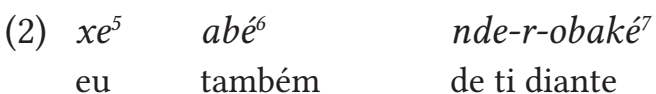

$a-\hat{\imath} \hat{u}^{8} \quad \hat{u} \mathrm{i}-\hat{\imath} e-m b$-ory'mb-ory'p-a ${ }^{9}$.

eu vim eu me alegrando muito.

$\begin{array}{llll}\text { (3) } k^{10} & x e \text {-anám- } a^{11} & r-u ́ r-i^{12} & p a^{13} \\ \text { aqui } & \text { meus parentes } & \text { vieram } & \text { todo }\end{array}$

nde-r-apé-pe $e^{14} \quad$ nde-r-epíák-a ${ }^{15}$;

teu caminho em te ver para;

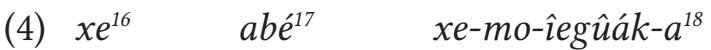

a mim também me enfeitaram

nde-mo-ory'-katú-potá ${ }^{19}$

te alegrar muito querendo.

(5) tapuy'f-pepy'r-a $\quad$ gû́ábo ${ }^{21}$

de inimigos banquetes comendo

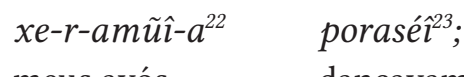

meus avós dançavam;

(6) $x e^{24} \quad$ Tup $\tilde{a}^{25} \quad r$-ekón $\hat{o}^{26} \quad a-\hat{i}-u s e ́ \hat{i}^{27}$,

eu de Deus costume eu o desejo,

$x e-r-u ́ b-a^{28} \quad r-e k o^{29} \quad$ peá-bo ${ }^{30}$

de meu pai costume afastando. 


\section{Tradução}

(1) Tu vieste, ó meu pai, para alegrar a minha terra!

(2) Eu também vim diante de ti, alegrando-me muito.

(3) Todos os meus parentes (toda a minha gente) vieram aqui ao teu caminho, para ver-te;

(4) e, querendo alegrar-te muito, enfeitaram-me a mim.

(5) Meus avós dançavam comendo banquetes de inimigos;

(6) eu porém desejo o costume de Deus e repilo o costume de meus pais.

\section{Análise}

1. xe-r-etám-a "minha terra": xe é o pronome da $1^{\mathrm{a}} \mathrm{s}$. da $1^{\mathrm{a}}$ classe. Os pronomes da $1^{\text {a }}$ classe são os seguintes: $1^{\mathrm{a}} \mathrm{s}$. xe, ixé, $1^{\mathrm{a}} \mathrm{p}$. excl. oré, $1^{\mathrm{a}} \mathrm{p}$. incl. îandé, $2^{\mathrm{a}}$ s. nde, endé, $2^{\mathrm{a}}$ p. pe. peĕ, $3^{\mathrm{a}}$ c. irrefl. $i, s-3^{\mathrm{a}}$ c. refl. o. Estes pronomes podem funcionar como sujeito, como objeto direto e como possessivo. Prefixados a um tema no aspecto nominal são possessivos; prefixados a um tema nominal (substantivo ou adjetivo) no aspecto verbal são sujeito; prefixados a um tema verbal no aspecto verbal são objeto direto. P. ex.: t. de subst. no asp. nom. anám-a "parente(s)", $1^{\text {a }}$ s. xe-anám-a "meu(s) parente(s)"; t. de subst. no asp. verb. anám "ter parente(s)", $\mathrm{l}^{\mathrm{a}}$ s. xe-anám "eu tenho parente(s)"; t. verbal no asp. verb. kutúk "ferir", $1^{\mathrm{a}}$ s. xe-kutúk "ferem-me". As formas ixé, endé, peĕ, entretanto, só se empregam independentemente, como sujeito enfático ou como sujeito de orações nominais: ixéxe-r-ory'b "eu eu estou alegre", ixé tupinambá "eu (sou) tupinambá". Em xe-r-etám-a, xe é possessivo.

$r$-é o prefixo de relação. etám é tema de substantivo da classe II. Há duas classes de temas: pertencem à classe I os temas que não recebem o prefixo de relação $r$-, e à classe II os que recebem esse prefixo. O prefixo ocorre sempre que o tema da classe II é precedido imediatamente por um substantivo que o determina ou por um pronome da $1^{\mathrm{a}}$ ou $2^{\mathrm{a}}$ pessoa da $1^{\mathrm{a}}$ classe. Quando o determinante é pronome da $3^{\mathrm{a}}$ pessoa não reflexiva, aos temas da classe I prefixa-se o pronome $i$, aos da II o pronome $s$-; quando é pronome da $3^{\mathrm{a}}$ pessoa reflexiva, prefixa-se o pronome $o$, sem o prefixo de relação. Exemplos:

\begin{tabular}{|c|c|c|}
\hline & a) t. anám I & "parente(s)" \\
\hline${ }^{a} \mathrm{~S}$ & xe-anám-a & "meu(s) parente(s)" \\
\hline${ }^{a}$ p. excl. & oré-anám-a & "nosso(s) parente(s)" \\
\hline${ }^{\mathrm{a} p}$ p. incl. & îandé-anám-a & "nosso(s) parente(s)" \\
\hline $2^{\mathrm{a}} \mathrm{s}$ & nde-anám-a & "teu(s) parente(s)" \\
\hline${ }^{a} \mathrm{p}$. & pe-anám-a & "vosso(s) parente(s)" \\
\hline ac. refl. & o-anám-a & "seu(s) próprio(s) parente(s)" \\
\hline c. irrefl. & i-anám-a & "parente(s) dele(s), dela(s)" \\
\hline
\end{tabular}




\begin{tabular}{|c|c|c|}
\hline & b) t. etám & "terra" \\
\hline $1^{\mathrm{a}} \mathrm{s}$ & xe-r-etám-a & "minha terra" \\
\hline $1^{\mathrm{a}} \mathrm{p} . \mathrm{cxcl}$. & oré-r-etám-a & "nossa terra" \\
\hline $1^{\mathrm{a}}$ p.incl. & îandé-r-etám-a & "nossa terra" \\
\hline $2^{\mathrm{a}} \mathrm{s}$ & nde-r-etám- $a$ & "tua terra" \\
\hline $2^{\mathrm{a}} \mathrm{p}$ & pe-r-etám-a & "vossa terra" \\
\hline $3^{\mathrm{a}}$ c.refl. & o-etám-a & "sua própria terra" \\
\hline $3^{\mathrm{a}} \mathrm{c}$. irrefl. & s-etám-a & "terra dele(s), dela(s)" \\
\hline
\end{tabular}

Esta classificação abrange os temas de substantivos, de adjetivos, de verbos e de posposições: substantivos, anám I "parente(s)" xe-anám-a "meu(s) parente(s)", etám II "terra" xe-r-etám-a "minha terra"; adjetivos, katú I "bom" $x e$-katú "eu sou bom", ory'b II "alegre" xe-r-ory'b "eu estou alegre"; verbos, kutúk I "ferir" xe-kutúk "ferem-me", ekár II "procurar" xe-r-ekár "procuram-me"; posposições, suí I "de" xe-suí "de mim”, esé II "por" xe-r-esé "por mim".

$-a$, índice nominal. Os temas de substantivos, adjetivos e verbos apresentam-se em dois aspectos: nominal e verbal. No aspecto nominal significam: a) os temas de substantivos - os nomes dos seres, b) os temas de adjetivos - os nomes das qualidades ou seres que possuem essas qualidades, c) os temas de verbos - os nomes dos processos (ações, estados, mudanças de estado). No aspecto verbal significam: a) os temas de substantivos - ter o ser nomeado, b) os temas de adjetivos - ter a qualidade ou ser da qualidade especificada, e) os temas de verbos - o desenrolar do processo indicado. Os temas terminados em vogal (temas vocálicos) ficam invariáveis em ambos os aspectos, não apresentando qualquer distinção morfológica, p. ex.: t. subst. kó I "roça", asp. nom. $x e$-kó "minha roça", asp. verb. xe-kó "eu tenho roça". Os temas terminados em consoante, porém, formam o aspecto nominal com o indice - $a$, enquanto ficam invariáveis no aspecto verbal, p. ex.: t. subst. anám I. "parente(s)", asp. nom.xe-anám-a "meu(s) parente(s)", asp. verb. xe-anam "eu tenho parente(s)".

2. mo-ory'p-a "para alegrar": mo-, prefixo causativo. Há, em Tupí, cinco vozes verbais simples. A voz causativa é formada pelo prefixo mo- : $m b o^{-}$. A alternância fonética $m$ - : $m b$ - é normal nesta língua. Neste texto ocorrem as duas formas do prefixo causativo, cf. 9. A voz causativa só pode ser formada sobre temas de verbos intransitivos; como os temas de substantivos e adjetivos no aspecto verbal constituem verbos intransitivos, também deles se forma a voz causativa; p. ex.: t. sém I "sair" caus. mo-sém "fazer sair; expulsar", t. subst. asp. verb. anám I "ter parentes" caus. mo-anám "fazer ter parentes", t. adj. asp. verb. ory'b II "estar alegre" caus. mo-ory'b "fazer estar alegre, alegrar". mo-ory'p-a é o gerúndio do verbo causativo mo-ory'b "alegrar". A formação do gerúndio varia segundo a terminação dos temas: 
a) os temas terminados em $-r$ perdem esta consoante: t. potár I "querer" ger. potá;

b) os temas terminados em outras consoantes e em semivogal recebem o sufixo -a: t. moñáng[-a] I "fazer" ger. moñáng-a, t. epîák II "ver" ger. epiák-a, t. poraséî I "dançar" ger. poraséî- $a$, t. mongaráû I "luxar” ger. mongaráû-a.

c) os temas terminados em $-b$, porém, mudam esta consoante em $p$ diante do sufixo -a: t. âusúb II "amar" ger. aûsúp-a, t. mo-ory'b I "alegrar" ger. moory'p-a;

d) os temas terminados em vogal recebem o sufixo - $a b o$; na junção deste ao tema, porém, verificam-se as seguintes particularidades fonéticas, decorrentes do encontro da vogal final do tema com a vogal inicial do sufixo:

$-a ́+a b o=-a ́ b o:$ t. îuká I "matar" ger. îukábo,

$-e ́+a b o=-e ́ b o:$ t. eé II "ralar" ger. eébo,

$-o ́+a b o=-o ́ b o:$ t. ó I "tapar” ger. óbo,

$-i+a b o=-\hat{a} a ́ b o:$ t. apití I "matar" ger. apitîábo,

$-u ́+a b o=-\hat{u} a ́ b o:$ t. peîú I "soprar" ger. peîuábo,

$-y^{\prime}+$ abo $=-y a ́ b o:$ t. $a b y$ ' I "errar" ger. abyábo;

e) se -ú não for procedido por consoante ou semivogal, resultará -gûábo: t. ú I "comer" ger. gûábo, t. suú I "morder" ger. sugûábo;

f) se a vogal final do tema for nasal ou nasalizada pela consoante precedente (toda vogal depois de consoante nasal é nasalizada), o sufixo se nasalizará, tomando a forma -(a)mo: t. nupã I "açoitar" ger. nupãmo, t. apyrõ II "chorar alguém" ger. apyrõmo, t. moñemū I "fazer pazes" ger. moñemûámo.

1-2. xe-r-etám-amo-ory'p-a "para alegrar minha terra": o objeto direto precede imediatamente o gerúndio dos verbos transitivos. Ao contrário do indicativo, p. ex., o gerúndio dos verbos transitivos não leva indicação do sujeito, o qual é sempre o mesmo do verbo principal do período. Se o tema pertencer à classe II, receberá o prefixo de relação: xe-r-etám-ar-epîák-a "para ver minha terra" (t. epîák II "ver"). Se o objeto não vier expresso por um nome, será representado por um pronome da primeira classe: $x e$-mo-ory' $p$ - $a$ "para me alegrar", xe-r-epîak-a "para me ver", i-mo-ory'p-a "para alegrá-lo", s-epî́k-a "para vê-lo".

3. ere-îú "tu vieste": ere é o pronome da $2^{\mathrm{a}}$ s. da segunda classe. Os pronomes da segunda classe são os seguintes: $1^{\mathrm{a}} \mathrm{s} . a, 1^{\mathrm{a}} \mathrm{p}$. excl. oro, $1^{\mathrm{a}} \mathrm{p}$. incl. $\hat{\imath} a, 2^{\mathrm{a}} \mathrm{s}$. ere, $2^{\mathrm{a}} \mathrm{p}$. pe, $3^{\mathrm{a}} \mathrm{c}$. o. Só funcionam estes pronomes como sujeito, em conjugação com os temas verbais no indicativo I e no permissivo.

îú é o mesmo que îur: é normal a queda de consoantes finais diante de palavras começadas por consoante. Aqui temos um verbo ditemático úr/îúr "vir". Os verbos tupís apresentam dois grupos de formas: a) formas remáticas ou propriamente verbais, que são o indicativo I ou indicativo remático, o permissivo, o imperativo, o gerúndio e o nome relativo; b) formas onomá- 
ticas, de natureza nominal, que são o indicativo II ou indicativo onomático, o subjuntivo e os nomes de ação, de agente, de circunstância, de objeto, de paciente e de agente habitual. São ditemáticos os verbos que apresentam dois temas diferentes, um para cada grupo de formas, portanto um tema remático e outro onomático. São poucos estes verbos, oito ou nove, os quais têm sido geralmente tratados como verbos "irregulares": ekó/ikó intr. "estar", én/ín intr. "estar sentado", eikéliké intr. "entrar", eity'k/ity'k trans. "derrubar, atirar", árl iár trans. "tomar, colher", úr/ îúr intr. "vir", úb/îúb intr. "estar deitado, jazer", eõ/manó intr. "morrer"; provavelmente também é/í trans. "dizer”. A primeira forma, em cada verbo, é onomática, a segunda remática: como se vê, esta última se caracteriza por um elemento $i$-; o único verbo que apresenta temas radicalmente distintos é eõ/manó.

Na espécie temos a $2^{\mathrm{a}} \mathrm{s}$. do indicativo I, portanto uma forma remática: ereîúr. O indicativo I dos verbos intransitivos é formado pela junção do pronome sujeito ao tema; em se tratando de tema verbal, como no caso em exame, o pronome é da $2^{\text {a }}$ classe, ao passo que, se o tema fosse nominal (substantivo ou adjetivo), seria da la classe. Tomando-se como, exemplo o tema só I intr. "ir", tem-se o paradigma do indicativo I dos verbos intransitivos:

$\begin{array}{lll}l^{\text {as. }} & a \text {-só } & \text { "eu fui" } \\ 1^{\mathrm{a}} \text { p. excl. } & \text { oro-só } & \text { "nós fomos" } \\ 1^{\mathrm{a}} \text { p. incl. } & \hat{\imath} a \text {-só } & \text { "nós fomos" } \\ 2^{\mathrm{a}} \mathrm{s} . & \text { ere-só } & \text { "tu foste" } \\ 2^{\mathrm{a}} \text { p. } & p e-s o ́ & \text { "vós fostes" } \\ 3^{\mathrm{a}} \mathrm{c} . & o-s o ́ & \text { "foi, foram" }\end{array}$

O indicativo não traz em si a indicação de tempo, a qual na verdade é estranha ao verbo tupí; caracteriza-se como um modo, que exprime a simples realização do processo verbal, em contraste com os outros modos, como p. ex. o imperativo, que designa ordem ou pedido para essa realização.

2-3. mo-ory'p-a ere-îú "tu vieste para alegrar". Distinguem-se três modalidades semânticas do gerúndio: a) gerúndio final, que exprime um processo (gerúndio) que representa a finalidade ou propósito de outro processo (verbo principal): a-sógûi-ñeéng-a "eu vou (a-só) para falar (gûi-ñeéng-a)"; b) gerúndio contemporâneo, que exprime que um processo (gerúndio) é realizado simultaneamente com outro processo (verbo principal): $a$-ñeéng gîui-xó-bo "vou falando", i. é, "falo (a-ñeéng) e vou (gûi-xó-bo) simultaneamente”; c) gerúndio aditivo, que exprime um processo (gerúndio) que é realizado pelo mesmo sujeito que já realizou outro processo (mas sem simultaneidade): xe-aîubán, xe-mo-mbytá-bo, kûár-apukúî o-kagú-ábo, o-poraséîa o-îegûák-a "abraçaramme (xe-aîubán, indic. I) e fizeram-me ficar (xe-mo-mbytá-bo, ger.), e durante todo o dia beberam cauim (o-kagû-ábo, ger.), dançaram (o-poraséî-a, ger.) e enfeitaram-se (o-îegûák-a, ger.)”. Na espécie temos um gerúndio final. 
4. $x e-r$-úb-y-gûé "ó meu pai!" xe-r-v. 1 úb tema de substantivo da classe II, significa "pai". Está no aspecto nominal, mas no vocativo, o qual, nos temas consoânticos, se caracteriza justamente pela ausência do índice nominal $-a$; assim, $x e-r$-úb-a quer dizer "meu pai", enquanto que $x e-r$-úb significa "ó meu pai!" Nos temas terminados em vogal, porém, o vocativo não apresenta qualquer distinção: $x e-s y$ " "minha mãe" e "ó minha mãe!" Há, porém, como é evidente, a distinção que se faz com a entonação própria do chamamento, além da que decorre do contexto, e que também distingue $x e-r$-úb vocativo de $x e-r$-úb aspecto verbal ("eu tenho pai"). Pode-se, entretanto, reforçar o vocativo com interjeições. Estas, como em geral as palavras de natureza emotiva, são diferentes para homens e para mulheres: os homens empregam gûé ou gûí, ao passo que as mulheres dizem ió ou îú; assim, xe-sy' gûé! na linguagem masculina e $x e-s y$ ' $\hat{\imath} u ́$ ! na feminina (a interjeição se pospõe ao vocativo). Quando o tema termina em consoante, desenvolve-se entre esta consoante e a da interjeição uma vogal anaptítica, muito breve, cujo timbre normal parece ter sido y: $x e-r-u ́ b-y$-gûé.

5. $x$ e "eu": pronome da $1^{\mathrm{a}} \mathrm{s}$. da primeira classe, empregado enfaticamente como sujeito de $a-\hat{\imath} u ́ u(8)$. Cf. 1.

6. abé "também".

7. nde-r-obaké "diante de ti": nde-r-v. 1 obaké "diante de", posposição, tema da classe II. As posposições tupís correspondem às preposições das línguas indo-europeias, mas sempre se pospõem à palavra que regem, seja esta pronome ou substantivo: xe-r-úb-a r-obaké "diante de meu pai", nde-r-obaké "diante de ti". Em geral elas têm origem nominal e nesta é fácil perceber um derivado de obá II "rosto, face".

8. a-îu "eu vim": $1^{\mathrm{a}} \mathrm{s}$. do indicativo I do verbo intransitivo ditemático úr/ îúr, v. 3. O - $r$ de $a$-îúr caiu diante da semivogal $\hat{u}$-, que se comporta como consoante; cf. também a observação abaixo sobre o emprego de $\hat{u} i$ em vez de gûu (9).

9. ûi-îe-mb-ory'-mb-ory'p-a "alegrando-me muito": ûi ou gûi é o pronome da $1^{\mathrm{a}} \mathrm{s}$. da $3^{\mathrm{a}}$ classe. Os pronomes da $3^{\mathrm{a}}$ classe são os seguintes: $1^{\mathrm{a}} \mathrm{s}$. gîu $i 1^{\mathrm{a}} \mathrm{p}$. excl. oro, $1^{\mathrm{a}}$ p. incl. $\hat{\imath} a, 2^{\mathrm{a}} \mathrm{s}$., $2^{\mathrm{a}} \mathrm{p}$. pe, $3^{\mathrm{a}} \mathrm{c}$. o. Como se vê, somente a $1^{\mathrm{a}} \mathrm{s}$. e a $2^{\mathrm{a}} \mathrm{s}$. diferem dos pronomes da $2^{\text {a }}$ classe. Estes pronomes se empregam com os gerúndios dos verbos intransitivos e, os da $2^{\mathrm{a}}$ pessoa, também com o imperativo. A alternância gîui : $\hat{u} i$ é normal (cf. Anchieta, 1933, ff. 4v., 28 v.); os portugueses registraram de preferência formas com g $\hat{u}$-, pois que em português é comum o fonema g $\hat{u}$, ao passo que os franceses anotaram especialmente $\hat{u}$ (cf. particularmente Abbeville, passim, e Léry, cap. XX). Aqui Anchieta empregou îi em vez de gûi provavelmente por causa da métrica, para conseguir a pronúncia de -îú ûi- numa só sílaba (observe-se que nos demais casos em que ocorre o mesmo fonema ele só empregou gîu : gûé(4), îegûák (17), gûábo (20)). 
$\hat{\imath} e$-, prefixo reflexivo. A voz reflexiva forma-se com a prefixação de $\hat{\imath} e$ - aos temas verbais transitivos; o prefixo é o mesmo para todas as formas do verbo e faz deste um novo verbo, intransitivo; assim, p. ex., do t. kutúk I trans. "ferir" obtém-se îe-kutúk I intr. "ferir-se", que se conjuga normalmente, como qualquer verbo intransitivo: $a-\hat{\imath} e-k u t u ́ k$, oro-îe-kutúk, $\hat{\imath} a-\hat{\imath} e-k u t u ́ k$, ere-îe-kutúk, pe-îe-kutúk, o-îe-kutúk "eu me firo, etc."

$m b$ - é o prefixo causativo $m b o-$, cuja vogal foi elidida diante da vogal inicial do tema ory'b: $m b$-ory'b portanto é o mesmo que mo-ory'b, v. 2. Aqui, pois, tem-se o mesmo verbo causativo já estudado acima, porém com o tema reduplicado. Há em Tupí duas espécies de reduplicação: a) reduplicação monossilábica, que consiste na repetição da última sílaba do tema, b) reduplicação dissilábica, que consiste na repetição das duas últimas sílabas do tema. A sílaba a ser repetida é a sílaba reduplicante, a que resulta da repetição é a sílaba reduplicada: se a sílaba reduplicante ou, no caso de reduplicação dissilábica, a última sílaba reduplicante terminar em consoante ou semivogal, perderá esse fonema final, que, entretanto, se conservará na (última) sílaba reduplicada; p. ex.: t. mokón I "engolir", red. monossil. mokó-kón, red. dissil. mokó-mokón. A reduplicação é um processo morfológico com que o Tupí exprime a intensidade, a frequência e o plural; este último é expresso pela reduplicação monossilábica (só nos verbos, formando o verbo plural, que indica a realização múltipla do processo, ou sucessiva, ou simultaneamente: mokó-kón "engolir muitas coisas sucessivamente", só-sók "quebrar-se por muitas partes, simultânea ou sucessivamente"); a intensidade e a frequência são expressas pela reduplicação dissilábica. A reduplicação dissilábica de temas verbais normalmente produz formas frequentativas, mas às vezes também forma o aspecto intensivo (aliás, a noção de frequência, de certa maneira, vem a identificar-se com a de intensidade: "falar frequentemente" equivale a "falar muito"):

t. mokón I "engolir", freq. mokó-mokón "engolir muitas vezes"; t. caus. moîegûák I "enfeitar", intens. mo-îeĝûa-îegûák "enfeitar muito, enfeitar bem"; t. caus. mbory'b I "alegrar", intens. mbory'-mbory'b "alegrar muito". Na espécie tem-se, pois, o aspecto intensivo. Este aspecto se forma não só por reduplicação dissilábica, mas também por incorporação de katú "bem" e de eté "muito"; abaixo vai-se encontrar o mesmo verbo mo-ory'b numa forma intensiva constituída com katú, v. 18.

$-a$ é o sufixo do gerúndio, cf. 2. A forma analisada $\hat{u} i-\hat{\imath} e-m b$-ory'-mb-ory'p-a é, pois, a $1^{\text {a }}$ s. do gerúndio, aspecto intensivo, voz causativo-reflexiva, de ory'b II "estar alegre". Para que melhor se perceba o processo de derivação, observem-se as etapas sucessivas desta síntese: (1) tema de adjetivo no aspecto verbal ory'b II "estar alegre", (2) voz causativa $m b$-ory' $b$ "fazer estar alegre, tornar alegre", (3) voz (causativo-) reflexiva $\hat{\imath} e-m b$-ory'b "tornar-se alegre", (4) 
aspecto intensivo îe-mb-ory'-mb-ory'b "tornar-se muito alegre", (5) gerúndio $\hat{\imath} e-m b$-ory'-mb-ory'p-a "tornando-se muito alegre", (6) la pessoa do singular $\hat{u} i-\hat{\imath} e-m b$-ory'-mb-ory'p-a "tornando-me muito alegre, alegrando-me muito".

10. kó "aqui".

11. xe-anám-a "meus parentes, minha gente": $1^{\mathrm{a}} \mathrm{s}$. do subst. anám I no aspecto nominal, cf. 1.1 .

12. $r$-úr-i "vieram": é o indicativo II do verbo úr/ îúr intr. "vir". O indicativo II só ocorre na $1^{\mathrm{a}}$ e na $2^{\mathrm{a}}$ pessoas e forma-se da seguinte maneira: a) aos temas vocálicos (terminados em vogal) acrescenta-se o sufixo - $\hat{u}, \mathrm{p}$. ex.: t. só I "ir" ind. II só $\hat{u}$, t. îuká I "matar" ind. II îukáû; b) aos temas consonânticos acrescenta-se o sufixo -i, p. ex.: t. kuáb I "saber" ind. II kuábi, t. úr II "vir" ind. II úr-i; c) os temas terminados na semivogal -î ficam inalterados (porque há absorção do sufixo -i pela semivogal -î), p. ex.: t. káîI "queimar-se" ind. II káî (< "káî̀-i). Se o tema for intransitivo, será precedido pelo nome do sujeito ou pelo res-

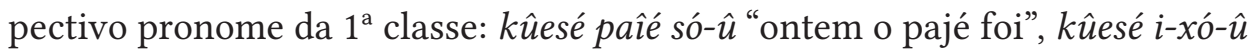

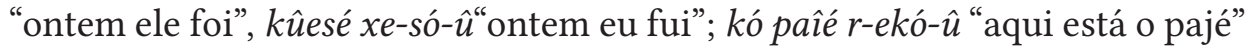

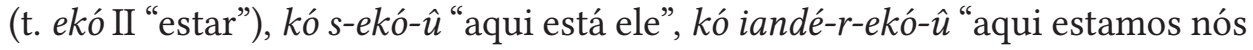
(incl.)". Se o tema for transitivo, será imediatamente precedido pelo nome do objeto ou pelo respectivo pronome da $1^{\text {a }}$ classe, e o sujeito ficará separado do verbo pelo objeto: kûesé paîe mbaé-asy'-bór-asubán-i "ontem o pajé chupou (t. subán I "chupar o doente") o enfermo (mbaé-asy'-bór-a)", kûesé paîe i-xu-bán-i "ontem o pajé o chupou", kûesé paîe xe-subán-i "ontem o pajé me chupou". O tema da forma em exame é o tema onomático úr (cf. 3), o qual é intransitivo e, como todos os temas onomáticos dos verbos ditemáticos, pertence à classe II, razão por que recebe o prefixo de relação quando é precedido imediatamente pelo nome do sujeito: $x e$-anám-a $r$-úr-i "meus parentes vieram".

10-11-12. kó xe-anám-a r-úr-i "aqui vieram meus parentes". O indicativo II exprime a realização do processo verbal quando subordinada a uma circunstância expressa; no presente caso a circunstância é expressa por kó "aqui".

13. pá "todos": esta partícula se pospõe aos verbos intransitivos para indicar que o processo interessa a todos os elementos sujeito e aos verbos transitivos para indicar que ele interessa a todos os elementos do objeto: kunumĩ $o$-só pá "foram (t. só I intr. "ir") todos os meninos", a-î-mo-ndó pá "enviei (t. caus. mo-ndó I trans. "fazer ir, enviar") todos".

14. nde-r-apé-pe "em teu caminho": t. apé II "caminho", na $2^{\text {a }}$ s. do aspecto nominal, cf. 1 -pe é o sufixo do locativo singular. Distinguem-se em Tupí quatro tipos de locativo: locativo singular, locativo plural, locativo de posição e locativo partitivo. O locativo singular indica direção (lugar para onde, aonde) e locação no espaço (lugar onde) e, às vezes, no tempo (tempo em que); forma-se com o sufixo -pe: $a$-sónde-kó-pe "eu vou à tua roça", îagûár-a

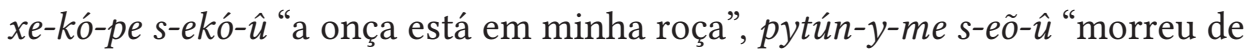


noite". Se o tema termina em - $b$, este cai diante do sufixo: t. táb I "aldeia" loc. sing. tá-pe "na aldeia"; se o tema termina em - $m$, este cai igualmente, e a vogal que o antecede, sendo nasalizada, nasaliza a consoante do sufixo $(p>m)$ : t. etám II "terra" loc. sing. $1^{\text {a }}$ s. xe-r-etá-me "em minha terra"; se o tema termina em qualquer outra consoante, intercala-se $y$ entre ele e o sufixo (cf. Anchieta, 1933, ff. 2, 42): t. ók II "casa” loc. sing. ók-y-pe "em casa", t. áng I "sombra” loc. sing. áng-y-me "na sombra", t. pytún "noite" loc. sing. pytún-y-me "de noite".

O locativo plural indica apenas locação, no espaço e no tempo, porém só no plural; forma-se com o sufixo -bo: kuña kó-bó s-ekó- $\hat{u}$ "as mulheres estão nas roças", kaá-bo îagûár-a r-ekó-ûu "as onças vivem pelo mato", kaburé pytún-y-bo i-bebé- $\hat{u}$ "o caburé voa de noite" (i. é, durante toda a noite, ou todas as noites). Também diante do sufixo - bo caem as consoantes labiais, entre outras consoantes e o sufixo intercala-se $y$ : t. táb I "aldeia" loc. pl. tá-bo "nas aldeias", II "casa" loc. pl. ók-y-bo "nas casas, pelas casas".

O locativo de posição indica a posição em que uma coisa está ou é colocada; forma-se com o prefixo $o$ - e o sufixo - $b o$ afixados simultaneamente ao tema: pitáng-a o-ĝu-atá o-pó-bo "a criança anda nas mãos, i. é, de gatinhas", ere-gûyapí o-kupé-bo "caíste de costas", o-pukú-botáb-a r-én-i "a aldeia está situada de comprido".

O locativo partitivo indica a parte do corpo ou de um objeto em que algo se acha ou é colocado; forma-se com o sufixo - $i$, o qual, nos temas terminados em -î, é absorvido por esta semivogal: xe-îúr-i a-r-ekó "tenho-o ao pescoço", o-î-mo-mbóritá y' r-obáî "ele atirou uma pedra na parte contrária do rio, i é, além do rio" (t. obáî II "parte contrária"). É limitado o número de nomes com que ocorre este locativo partitivo.

15. nde-r-epî́a-a "para ver-te": nde é o pronome da $1^{\mathrm{a}}$ classe da $2^{\mathrm{a}} \mathrm{s}$., funcionando como objeto direto, diante do tema verbal transitivo epîák II "ver" (v. 1-2). O verbo está no gerúndio, formado com o sufixo - $a$, e tem por sujeito o mesmo sujeito do verbo principal ( $r$-úr-i), que é xe-anám-a "meus parentes". Trata-se de um gerúndio final (cf. 2-3).

16. xe "me, a mim"; aqui o pronome da $1^{\text {a }}$ classe da $1^{\text {a }}$ s. está empregado como objeto direto enfático, reforço que é do objeto em xe-mo-îegûák-a (18).

17. abé "também".

18. xe-mo-îegûák-a "enfeitaram-me": xe é objeto direto; mo-, prefixo causativo (cf. 2); îegûák I "enfeitar-se", tema de verbo intransitivo, moîegûák é, pois, a voz causativa de îegûák e significa "fazer enfeitar-se", por conseguinte "enfeitar", O verbo está no gerúndio, caracterizado pelo sufixo - $a$; o objeto direto é xe e o sujeito é, ainda aqui, xe-anám-a (11). Este é um gerúndio aditivo.

19. nde-mo-ory'-katú-potá "querendo alegrar-te muito": aqui temos novamente a voz causativa do t. ory'b II "alegre"(cf. 2), que significa "fazer alegrar- 
se, tornar alegre, alegrar". $n d e$, pron. da $2^{\mathrm{a}} \mathrm{s}$. da $1^{\mathrm{a}}$ classe, é objeto direto. $\mathrm{O}$ tema katú I, incorporado aos temas verbais, denota o aspecto intensivo (cf.9); portanto, mo-ory'-katú significa "tornar muito alegre, alegrar muito" (na incorporação, que é um tipo de composição, a consoante final de um tema cai normalmente diante da consoante inicial de outro tema - cf. Dall'Igna Rodrigues, 1951c, pp. 65 e 69). O tema potár I "querer", incorporado aos temas verbais, forma o aspecto desiderativo. Este aspecto, que exprime o desejo que tem o sujeito de realizar o processo, pode formar-se de duas maneiras, a mais comum das quais é justamente com a incorporação de potár. t. só I "ir", desid. só-potár "querer ir", t. epiák II "ver" desid. epîa-potár "querer ver", t. moory'-katú I "alegrar muito" desid. mo-ory'-katú-potár "querer alegrar muito". A outra maneira de formar o desiderativo é com o sufixo -aúb reduplicado dissilabicamente (-aú-aúb): só-aú-aúb "desejar ir"; às vezes, porém, ocorre o sufixo simples: a-s-epîák-aúb "desejo vê-lo".

mo-ory'-katú-potár é, pois, uma forma desiderativo-intensiva do t. causativo mo-ory'b. No texto tem-se o gerúndio, caracterizado pela perda do $-r$ (cf. 2); o objeto direto é, como já se indicou, nde, e o sujeito é ainda o mesmo do indicativo II $r$-úr-i, i. é, xe-anám- $a$. Em comparação com 9, observe-se a síntese da forma ora examinada: (1) tema de adjetivo no aspecto verbal ory' $b$ II "estar alegre, alegrar-se", (2) voz causativa mo-ory'b "fazer alegrar-se, alegrar", (3) aspecto intensivo mo-ory'-katú "alegrar muito", (4) aspecto desiderativo mo-ory'-katú-potár "querer alegrar muito", (5) gerúndio mo-ory'-katú-potá "querendo alegrar muito", (6) $2^{\mathrm{a}} \mathrm{s}$. objeto nde-mo-ory'-katú -potá "querendo alegrar-te muito".

20. tapuy 'i-pepy'r-a "banquetes de inimigos": tapuy'î, tema de substantivo, cujo significado não é propriamente "inimigo", nem "escravo", como traduzem Paula Martins (1945, p. 85), o VLB (Anônimo, 1938, p. 218), Montoya (1876b, Tes., p. 355v./349v.), mas que, segundo nos parece evidente, designa toda pessoa que, para os Tupinambá, era suscetível de tornar-se vítima do sacrifício ritual; ora, como as vítimas eram normalmente os prisioneiros de guerra, todos os povos, ou pessoas pertencentes a esses povos, com os quais os Tupinambá faziam guerra, eram chamados tapuy'̂े-a: dai a acepção de "inimigos", aqui dada ao termo. O significado de "escravo", consignado pelo VLB e por Montoya, explica-se porque o prisioneiro, enquanto aguardava o dia da execução, permanecia (às vezes por muito longo tempo) numa situação que os observadores europeus identificaram com a escravidão e a que modernos sociólogos também chamam "escravidão" (cf. Fernandes, s. d., pp. 120-121, nota 415).

pepy'r I tema de substantivo, denota o banquete ou festim antropofágico. No texto, forma um composto determinativo (cf. Dall'Igna Rodrigues, 1951c, p. 66) com o tema tapuy'î, significando "banquete(s) de inimigos". O composto 
está no aspecto nominal, que se caracteriza pelo índice - $a$, e é objeto direto de $g \hat{u}-a ́ b o(21)$.

21. gîu-ábo "comendo": é o gerúndio (contemporâneo) do t. ú I "ingerir, comer ou beber", transitivo (irregular). Para a formação do gerúndio, v. 2. O objeto direto é tapuy'̂̀-pepy'r-a, o sujeito é o mesmo do indicativo II poraséî, portanto $x e-r$-amũ̂े-a (22).

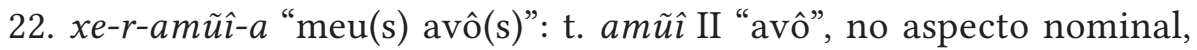
$1^{\mathrm{a}} \mathrm{s}$.

23. porasêî "dançava(m)": t. porasêî I intr. "dançar"; está no indicativo II, cuja característica, o sufixo -i, é absorvida pela semivogal -î do tema ( ${ }^{*} p o-$ rasé̂́- $i>$ poraséî) (cf. 12). Tem por sujeito xe-r-amũ̂̀-a. O indicativo II está subordinado à circunstância expressa pelo gerúndio gûúábo (21), o qual, como gerúndio contemporâneo que é, pode traduzir-se em português por uma oração subordinada temporal: "enquanto comiam banquetes de inimigos, meus avós dançavam".

24. xe "eu": pronome da $1^{\mathrm{a}} \mathrm{s}$. da $1^{\mathrm{a}}$ classe, sujeito enfático de a-î-uséî (27). Poder-se-ia interpretar, também, como possessivo, ligado a Tupã: xe-Tupã "meu Deus", com o que o sentido da oração em que se encontra seria "eu desejo o costume de meu Deus".

25. Tupã "Deus": tema da classe I. Na realidade o tema é tupán I (asp. nom. tupán-a) e era, originalmente, o nome de um gênio que causava as tempestades, os trovões e os relâmpagos (cf. Métraux, 1928, pp. 52-55), razão por que o trovão era chamado tupã-sunúng-a "estrondo de tupána" e o relâmpago tupã-mberáb-a "brilho de tupána" (cf. Marcgrave, 1942, p. 278). Os missionários associaram os atributos desse gênio, que vivia nos ares, no céu, com os de Deus, e adotaram seu nome para designar a divindade cristã (cf. Métraux, 1928, p. 56). Entre os missionários porém, e em seguida entre os próprios índios catequizados, o nome tomou a forma tupã (em vez de tupán-a), talvez por influência analógica de compostos como os citados tupã-sunúng-a, e túpã-mberáb-a (em que a consoante final do t. tupán cai diante da consoante inicial do tema seguinte, nasalizando a vogal precedente), ou por influência dos dialetos meridionais, em que era frequente a queda da consoante final dos temas consonânticos (cf. Anchieta, 1933, f. 1v.) (donde t. tupán > tupã) e em que os temas, assim desprovidos da consoante, provavelmente poderiam comportar-se como temas vocálicos, portanto invariáveis no aspecto nominal (donde asp. nom. tupán-a substituído por tupã; cp. o Guarani antigo amã o-ky "chove" - Montoya, 1876b, Tes., p. 29 v. - correspondente ao Tupi amán-a $o-k y^{\prime} r$ ).

26. r-ekó "o costume": t. ekó II, com o prefixo de relação porque vem precedido imediatamente pelo nome Tupã, seu determinante (cf. 1). Aqui ekó é o nome de ação do verbo ditemático ekó/ikó "estar, viver"; todo verbo no 
aspecto nominal constitui um nome de ação, o qual, nos verbos ditemáticos forma-se do tema onomático (cf. 3). Como nome de ação, ekó significa "estado, vida, costume".

27. a-î-usế "eu o desejo": $1^{\mathrm{a}} \mathrm{s}$. do indicativo I do t. trans. usế̂ I "desejar". $a$-, pronome da $1^{\text {a }}$ s. da $2^{\text {a }}$ classe, é o sujeito (cf. 3 ); $i$-, pronome da $3^{\mathrm{a}} \mathrm{c}$. irrefl. da $1^{\text {a }}$ classe, é o objeto direto: no indicativo I dos verbos transitivos, bem como no permissivo e no imperativo, o objeto direto, representado por pronome da $3^{\mathrm{a}} \mathrm{c}$., é incorporado à forma verbal, situando-se entre o pronome sujeito e o tema. Se o tema for da classe I, receberá o pronome $i-$, se da classe II, receberá o pronome $s$ - (cf. 1): t. uséî I "desejar", las. ind. I a-î-usếi "eu o desejo"; t. ekár II "procurar", $1^{\mathrm{a}} \mathrm{s}$. ind. I a-s-ekár "eu o procuro". Nunca se pode empregar o indicativo I, o permissivo ou o imperativo de um verbo transitivo sem a incorporação do objeto direto. Sendo este da $3^{\mathrm{a}} \mathrm{c}$. e vindo expresso por um substantivo, poderá enunciar-se a oração de duas maneiras: a) ou com a incorporação do substantivo: a-ybá-usêî "eu desejo frutas", a-ybá-ekár "eu procuro frutas", b) ou, o que é mais frequente, com a incorporação do pronome e a enuncia-

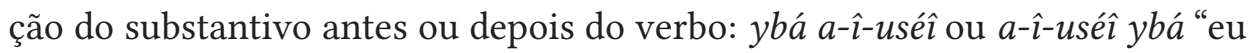
desejo frutas", a-s-ekár ybá "eu procuro frutas”, Tupã r-ekó a-î-usêî “eu desejo o(s) costume(s) de Deus" (lit. "de Deus costume(s) eu o(s) desejo").

28. $x e-r$-úb-a "meu pai": t. úb II "pai", no aspecto nominal, da $1^{\mathrm{a}} \mathrm{s}$. cp. $x e-$ -r-etám-a, 1.

29. $r$-ekó “o(s) costume(s)": v. 26. Aqui o determinante é $x e-r$-úb-a. (28): xe-r-úb-ar-ekó "o(s) costume(s) de meu pai".

30. peá-bo "afastando, repelindo": t. peá I trans. "afastar", no gerúndio (cf. 2); tem por objeto direto xe-r-úb-ar-ekó e por sujeito o mesmo sujeito de $a$ i-uséî (27), a $1^{\mathrm{a}} \mathrm{s}$. Trata-se de um gerúndio contemporâneo: a-î-uséî ... peá-bo "eu o desejo... e afasto..." (simultaneamente).

\section{Notas Finais}

1) Posteriormente à publicação de Poesias Tupis (Paula Martins, 1945), a Dra. Paula Martins publicou nova tradução da "Dança de Dez Meninos", no opúsculo Anchieta, I - Poesias. Introdução, seleção e notas por M. de L. de Paula Martins, Peq. Bibl. de Literatura Brasileira, I., São Paulo, s. d..

$\mathrm{Na}$ tradução das estrofes aqui estudadas foram introduzidas duas modificações as quais, parece-nos, não foram vantajosas; uma, pelo contrário, afasta-se do original, quando a tradutora substitui, no segundo verso, "ó meu pai!" por "ao meu encontro".

2) Sobre a chegada ao Brasil do Pe. Marçal Beliarte, para cuja recepção foi composta a peça, vide Fernão Cardim, Tratados da Terra e Gente Brasil. Introdução e notas de B. Caetano, C. de Abreu e R. Garcia. 
Brasiliana, vol. 168, $2^{\text {a }}$ ed., S. Paulo - Rio-Recife - P. Alegre, 1939, pp. 320-321; e Serafim Leite, S. J., História da Companhia de Jesus no Brasil, t. I, Lisboa - Rio, 1938, p. 569. 